$L C L S-T N-06-2$

\title{
Air Temperature in the Undulator Hall *
}

\author{
J. Welch
}

January 12, 2006

\section{Contents}

\section{Introduction}

1.1 Undulator Hall HVAC System . . . . . 1

1.2 Analyses Performed . . . . . . . . . . 1

1.3 1-D Assumption . . . . . . . . . . 2

1.4 Heat Transfer Coefficient . . . . . . . 2

2 Performance Estimates 4

2.1 Normal Operation . . . . . . . . . 4

2.2 Access . . . . . . . . . . . . 4

2.3 Long Term and Seasonal Behavior . . 4

2.4 Effect of Air Temperature on Equipment 5

\section{Upgrade Scenarios}

\section{A Welch Access Loads}

\section{Introduction}

Various analyses have been performed recently to estimate the performance of the air conditioning (HVAC) system planned for the Undulator Hall. This reports summarizes the results and provides an upgrade plan to be used if new requirements are needed in the future. The estimates predict that with the planned loads the tunnel air temperature will be well within the allowed tolerance during normal operation.

*Work supported in part by the DOE Contract DE-AC0276SF00515. This work was performed in support of the LCLS project at SLAC.

\subsection{Undulator Hall HVAC System}

A recirculating HVAC system with a flow rate of 20,000 cfm was chosen for the Undulator Hall. A single square duct carries air from the east end to the west end of the tunnel where it is discharge into the tunnel. The air in the tunnel flows from west to east only. At the east end the air is removed from the tunnel and recirculated to a pair of 10,000 $\mathrm{cfm}$ air handler units (AHU). The air handler units condition the air to the desired temperature to maintain a constant discharge temperature into the tunnel of $68^{\circ} \mathrm{F}\left(20^{\circ} \mathrm{C}\right)$. As the air flows in the tunnel it picks up heat from various equipment sources and, in some cases lighting, as well as loses heat to the cool tunnel 5 walls and floor and other heat sinks. The average air temperature as it flows down the tunnel is the 8 determined by a balance of the heating and cooling sources.

\subsection{Analyses Performed}

Separate analysis were carried out by Kleyn [1], Sharma [2], Welch, and Worek [3]. The analyses had in common an assumption of perfect mixing of the tunnel air within any cross section at any point along the tunnel, but they differ in their estimates of the heating and cooling sources. Differences in heating loads used are attributable to different choices of operating conditions and different estimates used for the amont of power generated by the equipment. More significantly, the differences in cooling loads used are attributable to different estimates for the heat transfer coefficient which governs the exchange of heat be- 
tween the air and a surface held at a given temperature, and different assumptions about the ambient ground temperature. These issues are discussed below.

\subsection{1-D Assumption}

Perfect mixing of the tunnel air within any cross section at any point along the tunnel means that at any given distance along the tunnel, the local heat and cooling sources are added together and only the net heat is used to calculate the change in the average local air temperature. This essentially 1-D assumption implies only the balance of heating and cooling sources at any given tunnel distance is signficant.

In reality the air will not be perfectly mixed. Air near cool walls will be significantly cooler than average. Air near heat sources will be significantly warmer. However, the average flow velocity in the tunnel is such that the Reynolds number, evaluated at the tunnel diameter, is 140,000, which indicates fully turbulent flow. This turbulence should effectively mix the air within a few tunnel diameters (diameter is $5.79 \mathrm{~m}$ ) of distance along the tunnel. So the 1-D/perfect mixing approximation is valid if it is understood that the air temperature it predicts is a one-side average over a few tunnel diameters distance.

\subsection{Heat Transfer Coefficient}

One of the most important inputs into the calculations is the estimate of the heat transfer coefficient $h$ between the air and the tunnel walls and floors. A boundary layer of air will form between the main air flow in the tunnel, which is at the nominal velocity of $0.45 \mathrm{~m} / \mathrm{s}$, and the tunnel wall. At the surface of the wall the velocity of the air approaches zero and the only heat transfer mechanism at work is conduction through still air. Since still air is an excellent insulator, a steep temperature gradient may be required in the boundary layer to conduct heat from the main air stream to the tunnel wall. Consequently there can easily develop substantial temperature differences between surface of the tunnel walls and the main air stream for a given amount of heat flux being transported. The heat transfer coefficient is a convenient means to describe the overall effect of the boundary layer on the net heat transfer. It is defined as the net heat flux divided by the temperature difference between the surface of the wall and the main air stream. Outside the boundary layer, the dominating heat transfer mechanism is by mass flow rather than conduction. This much more efficient heat transfer mechanism results in nearly uniform temperature across the main air stream.

Estimates for the value of $h$ are usually found from measured correlations, though than can be measured directly. The correlations are given in terms of dimensionless variables so that the principle of 'similarity' can be employed. This is nothing more than a statement that if two physical situations have the same shape (not necessarily the same size, viscosity, speed, etc), then the relationship between the various dimensionless numbers is unique. Thus if the correlation of the dimensionless variables is measured for the shape of interest, the results can be easily applied to other sizes, fluids, temperatures, etc. In practice however, measured correlations are easy to find for only the simplest shapes and not for the exact shapes of interest. In such cases there must be a leap of faith that the shapes are too different. In our case, correlations exist for axial flow through a round duct (tube), but not with the shape of our tunnel.

Forced vs. Free Convection Most of the analysis assumed that the dominant heat transfer mechanism to the tunnel walls is based on solely on forced convection. On theoretical grounds it can be seen that the relative importance of bouyancy, which is the driving force in free convection, to forced convection heat transfer is qualitatively given by the ratio of the Grashof Number ( $\mathrm{Gr}$ ) to the square of the Reynolds number (Re).[4] If $G r / R e^{2} \sim 1$ then free convection may be significant. The Grashof number is proportional to the difference in temperature between air and the wall. If we assume this temperature difference is $1 \mathrm{C}$, which is appropriate for initial operation, then $G r / R e^{2}=0.8$ so there may be significant free convection contribution to the heat transfer. However, in the particular case of a vertical 
plate, it has been shown that free convection is negligible even when $G r / R e^{2}>10$ so perhaps the theoretical estimate is not precise enough and somewhat overestimates the importance of free convection heat transfer. The uncertainty in the extent to which free convection plays a role in the heat transfer is reflected in the range of different estimates for the tunnel air temperature.

Radiative Heat Transfer Generally radiative heat transfer was assumed to be insignificant in the analyses except for that of Worek, who assumed it played an important role in generating a higher effective heat transfer coefficient. All analyses predict temperature differences between the air and the walls of order $1{ }^{\circ} \mathrm{C}$ or less. With the assumption of perfect black body emission (maximum radiative power) such small differences in temperatures can produce radiative heat fluxes only of order $6 \mathrm{~W} / \mathrm{m}^{2}$ or less. Nevertheless this is more than the heat flux expected through the tunnel walls due to convective heat transfer (See Figure 1 for example). However, air is largely transparent to thermal radiation. For example, thermal radiation produced by a warm piece of equipment will radiate directly to the cool tunnel walls without being absorbed first by the air in between. So, while radiative heat transfer should not be significant in changing the air temperature, it is significant in determining the steady state temperatures of the walls and the equipment. Generally radiative heat transfer will tend to locally bring steady state temperatures of equipment and walls closer together.

Ground Temperature The tunnel walls and floor are the main source of cooling in all the models but the models differ substantially on what temperatures were assumed for the walls and floor. Values used ranged from $15{ }^{\circ} \mathrm{C}$ to $19{ }^{\circ} \mathrm{C}$. Information from the USGS from two monitoring wells in the area indicate that the soil temperature at the depth of the deep part of the tunnel is about $18{ }^{\circ} \mathrm{C}$. Once the HVAC system is started and the air is held near $20{ }^{\circ} \mathrm{C}$ the walls and floor will start to warm up. The rate at which they warm up depends on soil properties as well as the heat transfer coefficient. An ANSYS cal-

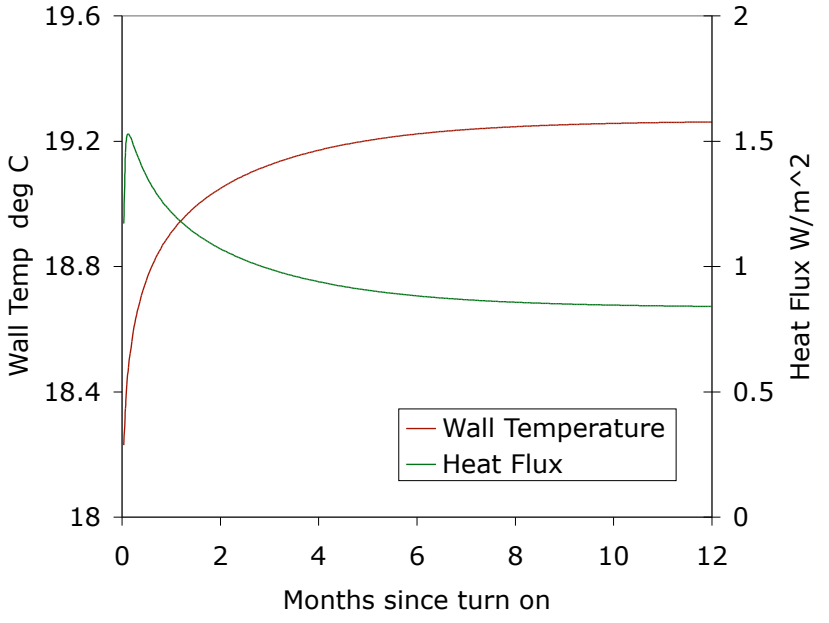

Figure 1: Estimated tunnel wall temperature and heat flux for the first year of operation.

culation by Welch of the tunnel wall and surrounding ground temperature based on a simplified tunnel geometry, (round cross section, no surface effects), but with realistic soil properties [5], [6] is shown in Figure 1. A quasi-static value for the wall temperature, approximately $19.2 \mathrm{deg} \mathrm{C}$ is reached in roughly three months after the HVAC system is turned on. This estimate is based on a heat transfer coefficient of $1.2 \mathrm{~W} / \mathrm{m}^{2}$ which is commensurate with the estimates of Welch, SCS, and Sharma. The same calculation with a higher heat transfer coefficient effectively compresses the time scale so the quasi-static state is reached sooner. With a higher heat transfer coefficient the wall temperature comes closer to the air temperature, but this effect is offset by the higher heat transfer rate which warms the wall more quickly, so the net wall cooling is only slightly higher than in the case of the relatively low heat transfer coefficient. A factor of 4 increase in $h$ leads to only about a $30 \%$ increase in the wall cooling rate. Thus, the cooling rate of the tunnel walls is not particularly sensitive to the heat transfer coefficient. 


\section{Performance Estimates}

The predictions made apply to specific operating conditions and loads. Two representative conditions are defined as 'Normal Operation" and 'Access'. Normal operation is meant to represent conditions when beam is delivered to the Undulator Hall and xrays are being produced and sent to the FEE. 'Access' is meant to represent conditions when there is permitted access to the Undulator Hall, people are present and presumably engaged in some activity.

\subsection{Normal Operation}

The SCS prediction for the heat balance under normal operating conditions using 'most probable' estimates for heat loads (rather than worst case estimates) is shown in Figure 2. Both the temperature of the air in the supply duct and the temperature of the air in the tunnel are shown. The supply duct air heats up mainly due to friction as it traverses the duct through the tunnel. Tunnel air starts at $20.0{ }^{\circ} \mathrm{C}$ and warms approximately linearly to a maximum of $20.13{ }^{\circ} \mathrm{C}$ which is at the end of the installed equipment, and then falls back a bit before it reaches the return ducting. This model predicts the tunnel air will be well within tolerance of $\pm 0.56{ }^{\circ} \mathrm{C}$. The wall temperature assumed was $19{ }^{\circ} \mathrm{C}$, which is appropriate for the first year of operation. As the wall slowly warms over the first few months of operation the peak temperature of the air will rise as well.

A detailed list of the loads assumed in the SCS calcuation is given in their report [1]. The equipment portion of these loads were generated by Pile, et. al. at Argonne. A pictorial example of the equipment heat loads is shown in Figure 5. Loads due to conventional facilities were partially supplied to SCS by Welch and partly calculated directly from the specifications of the chilled and hot water lines (insulated), and duct specifications. The most notable features are:

- Alignment electronics was assumed to be water cooled with $90 \%$ efficiency, leaving only $80 \mathrm{~W} /$ rack going into the air

- Lights are off

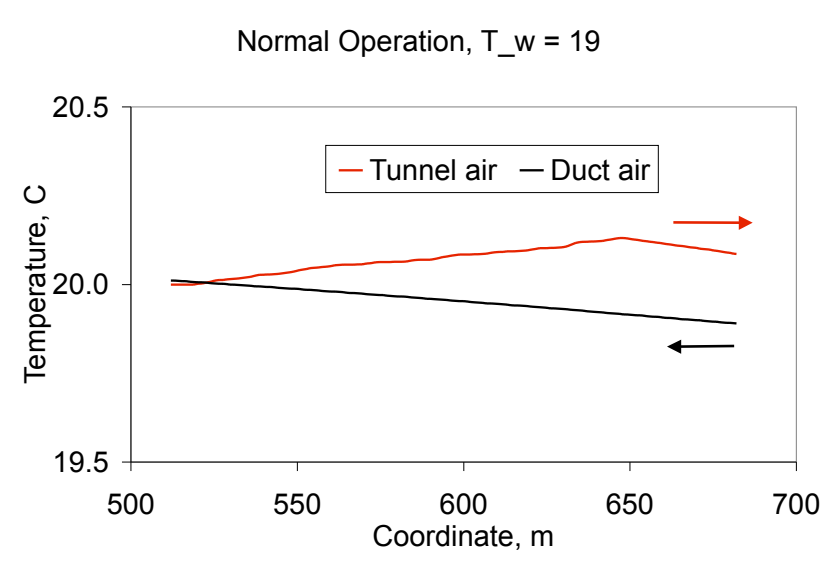

Figure 2: SCS estimate for normal operations.

- Quadrupoles are water cooled

- Low power line transmission loss

\subsection{Access}

A load case was developed to represent the most probable loads during tunnel access when lights are turned on and people are in the tunnel. The Welch prediction for the tunnel air temperature during access is shown in Figure 3. The biggest change in load between normal operation and access is due lighting, which is off during normal operation and on during access. The discharge temperature was dropped to about $19.5{ }^{\circ} \mathrm{C}$ so that the temperature swings on the undulator components is minimized. The overall air temperature stays just within the nominal operating tolerance, but is well within the tolerance on the maximum temperature exposure of the undulator segments $\left( \pm 5^{\circ} \mathrm{C}\right.$. $)$ This estimate assumed 19 degree $\mathrm{C}$ walls. A complete list of the heat loads assumed for this case is in Appendix A.

\subsection{Long Term and Seasonal Behavior}

In the deeper parts of the tunnel, which roughly constitute roughly $85 \%$ of the length of the undulator, the annual temperature variation in undisturbed soil is expected to be less than $\pm 0.25^{\circ} \mathrm{C}$. This estimate is 


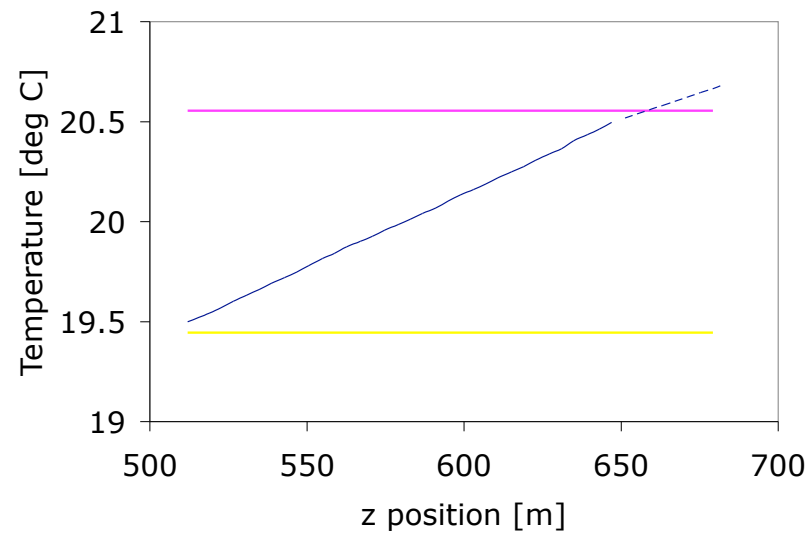

Figure 3: Welch estimate for Access conditions. The horizontal lines represent the tolerance limits for Normal Operation.

based on measurements from two nearby wells maintained by the USGS taken at different times of the year about six months apart, which are shown in Figure 4. Differences in local conditions, such as sun exposure and water table heights can cause small differences in the ground temperature profiles at the level of $\sim 0.1^{\circ} \mathrm{C}$.

\subsection{Effect of Air Temperature on Equipment}

Ultimately we are interested in the temperature that Undulator components come to in the tunnel and how much and how fast they change with changing tunnel conditions. None of the equipment is directly temperature controlled so the temperature a piece of equipment comes to is determined by the balance of heating and cooling with the tunnel air being one element of the balance. Additional sources of heating and cooling are conduction to other pieces of equipment and the floor, thermal radiation (as discussed in Section 1.4), and heat generation by the equipment, for example resistive heating. All sources of heating and cooling need to be evaluated before the steady state temperature of the devices can be calculated. The range of steady state temperatures of equipment can be expected to be somewhat different from than

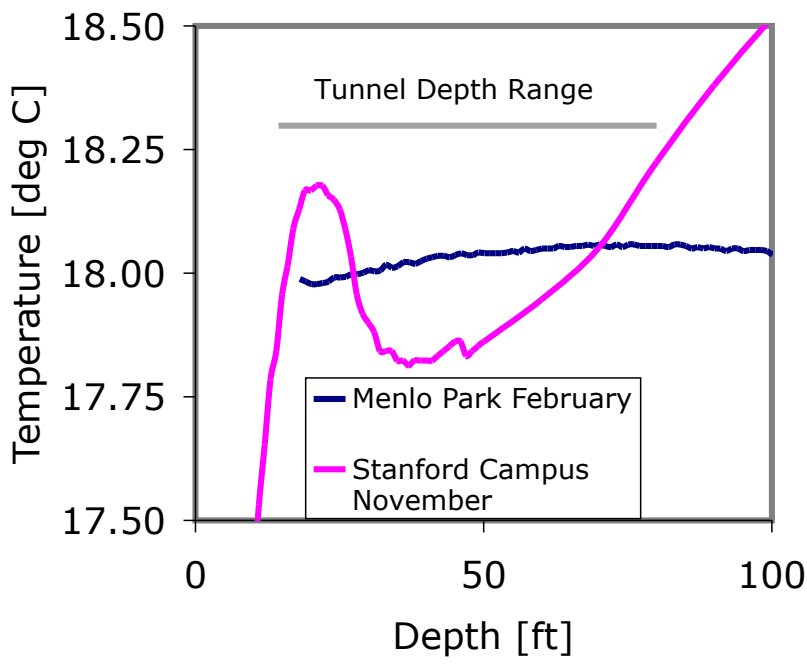

Figure 4: USGS soil temperature measurements.

the temperature range of the air. In some cases, especially where the equipment generates heat, the range of steady state temperatures can be greater than the range of air temperatures.

\section{$3 \quad$ Upgrade Scenarios}

If in the future substantially increased heat loads or substantially decreased temperature tolerances are desired, there is a straightforward path to handle the new demands. Chilled and hot water lines are planned to pass through the Undulator Hall to supply chilled water to the service buildings in the Research Yard. There is extra capacity in these lines. A series of isolation valves, 13 pairs in all, are to be installed near the large break locations of the undulator magnets. This arrangement provides a robust source of cooling power that can be tapped as needed in the future. Depending on the future requirements, additional cooling demands can be met by as simply as connecting fin cooled heat exchangers and manually setting the flow rate. Or, it can be more sophisticated by adding a variable heater in series with the heat exchanger so that localized feedback can be employed. This latter arrangement would make it 
possible to regulate the air temperature even in the presence of time varying heat sources. Because the stub-outs are will be in place after construction of the tunnel, the chilled water system wouldn't need to be drained to install additional equipment, thus minimizing any impact such an upgrade might have on other systems availability.

\section{Acknowledgments}

The author would like to acknowledge the substantial contributions of Colin Williams, Joseph Kleyn, Bill Worek, Sushil Sharma, Marvin Kirshenbaum, and Javier Sevilla.

\section{References}

[1] LCLS Undulator Hall Tunnel Thermal Performance Analysis, SCS-SLAC-R-0001, J. Kleyn. From SCS Solutions, Sunnyvale Ca.,12/21/05, $46 \mathrm{p}$.

[2] Presentation "Heat Balance in the LCLS Tunnel", S. Sharma, 12/12/05, 12p

[3] "Analysis of the Heating and Cooling Requirements of the Undulator Hall at SLAC", W. Worek,12/9/05, 16p.

[4] F. Kreith, Principles of Heat Transfer, Intl Textbook Co., 1967, pp 358

[5] Colin Williams, Heat Flow Studies, Earthquake Hazards Team, U.S. Geologicial Survey, estimated the thermal conductivity to be about 2.5 $\mathrm{W} / \mathrm{m}^{\circ} \mathrm{C}$.

[6] Gerard Aarons, SLAC, examined 20 or so borehole geophysical logs in the Ladera Sandstone and stated the thermal conductivity is generally in the range of 2.25 to $3.25 \mathrm{~W} / \mathrm{m}^{\circ} \mathrm{C}$. 

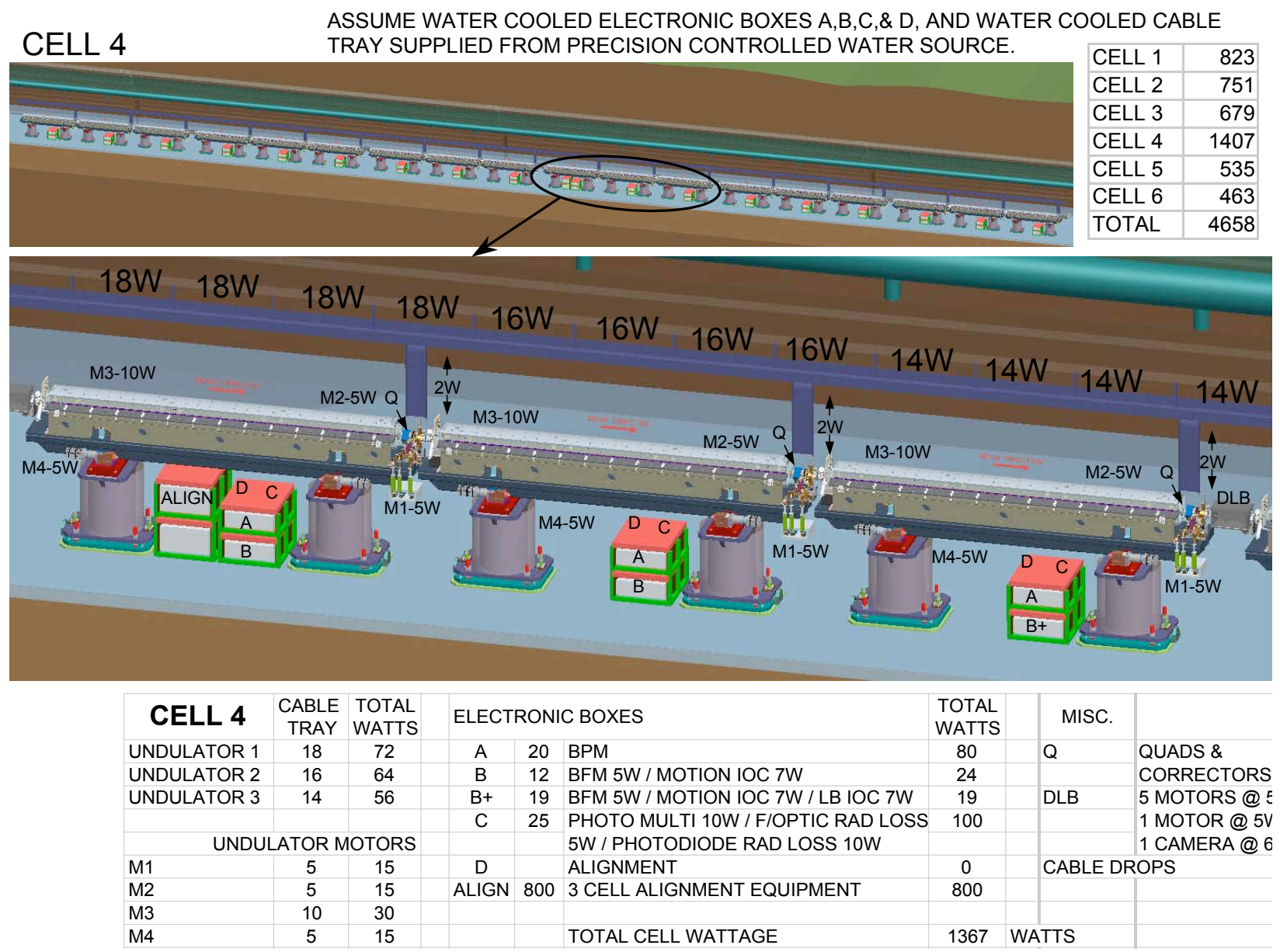

Figure 5: Example of equipment loads from Undulator System 


\section{A Welch Access Loads}

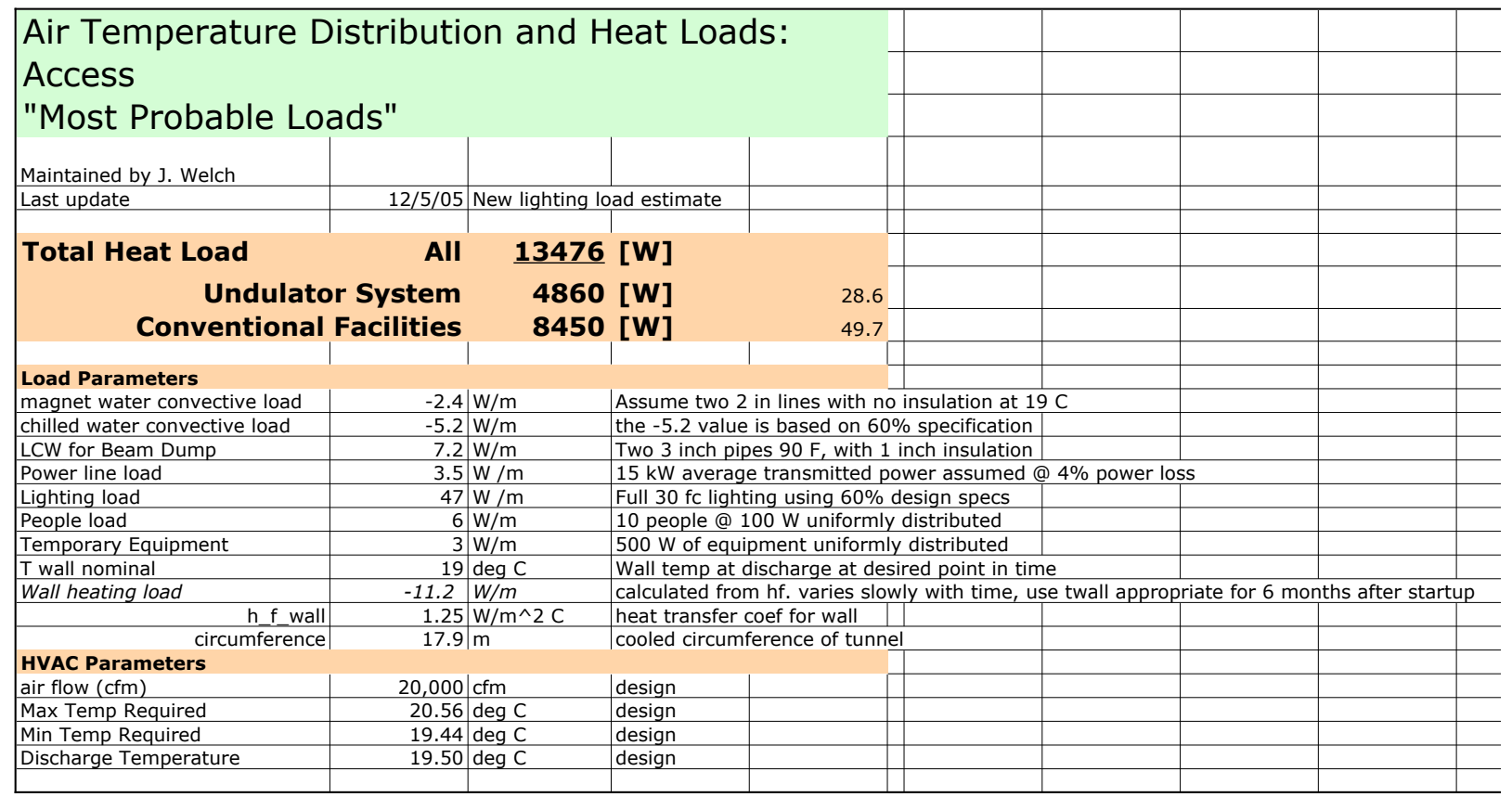

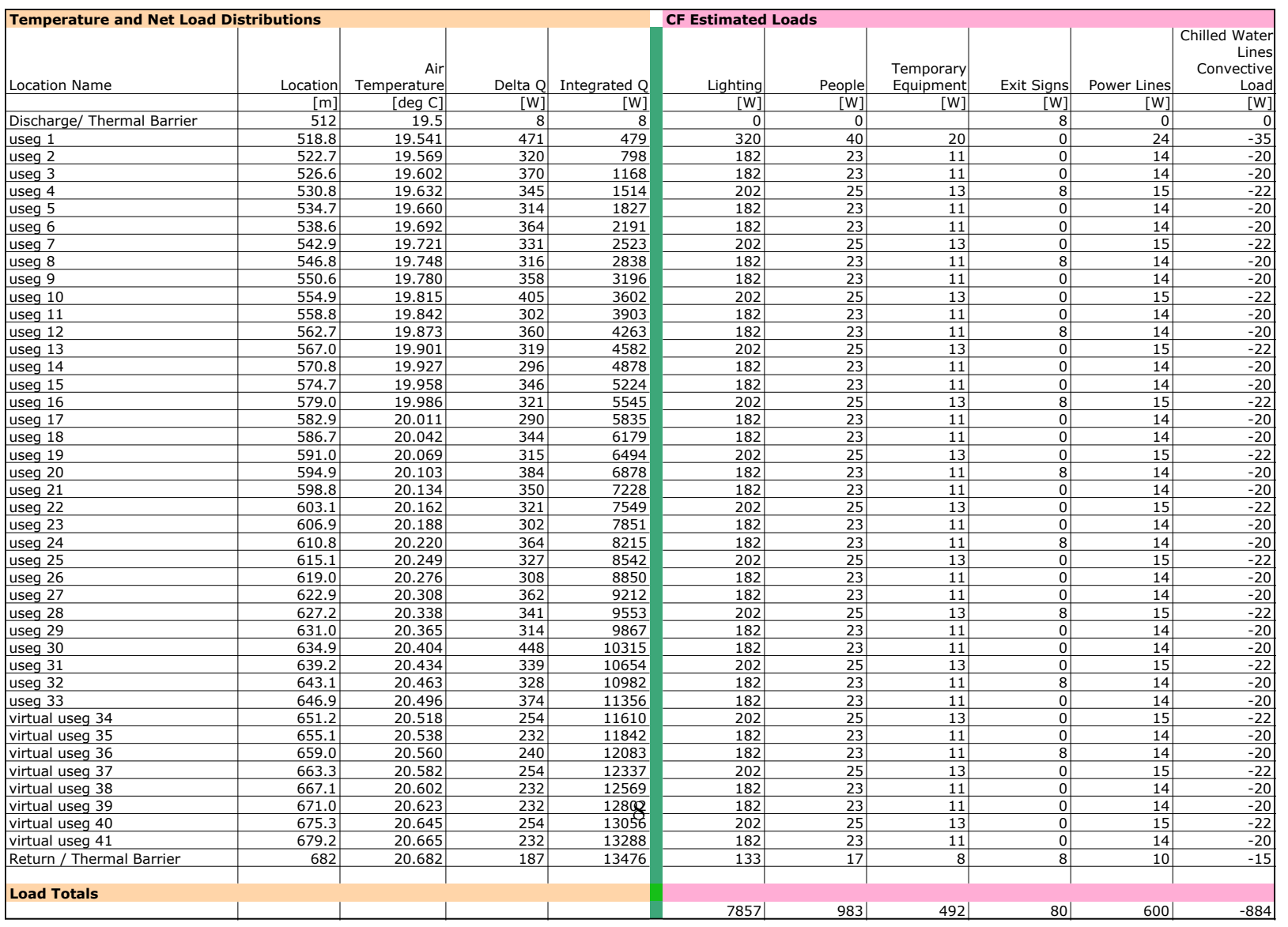




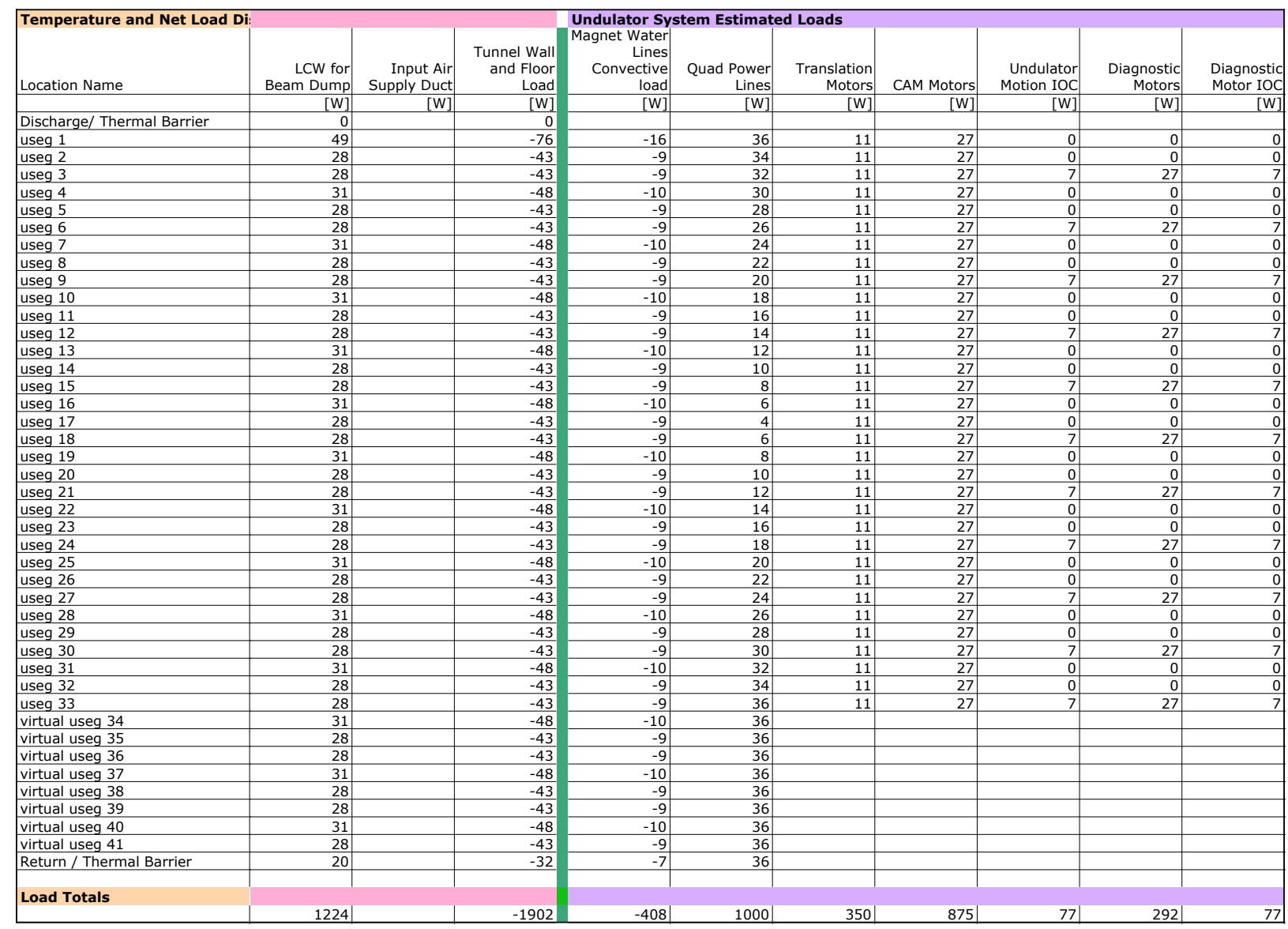




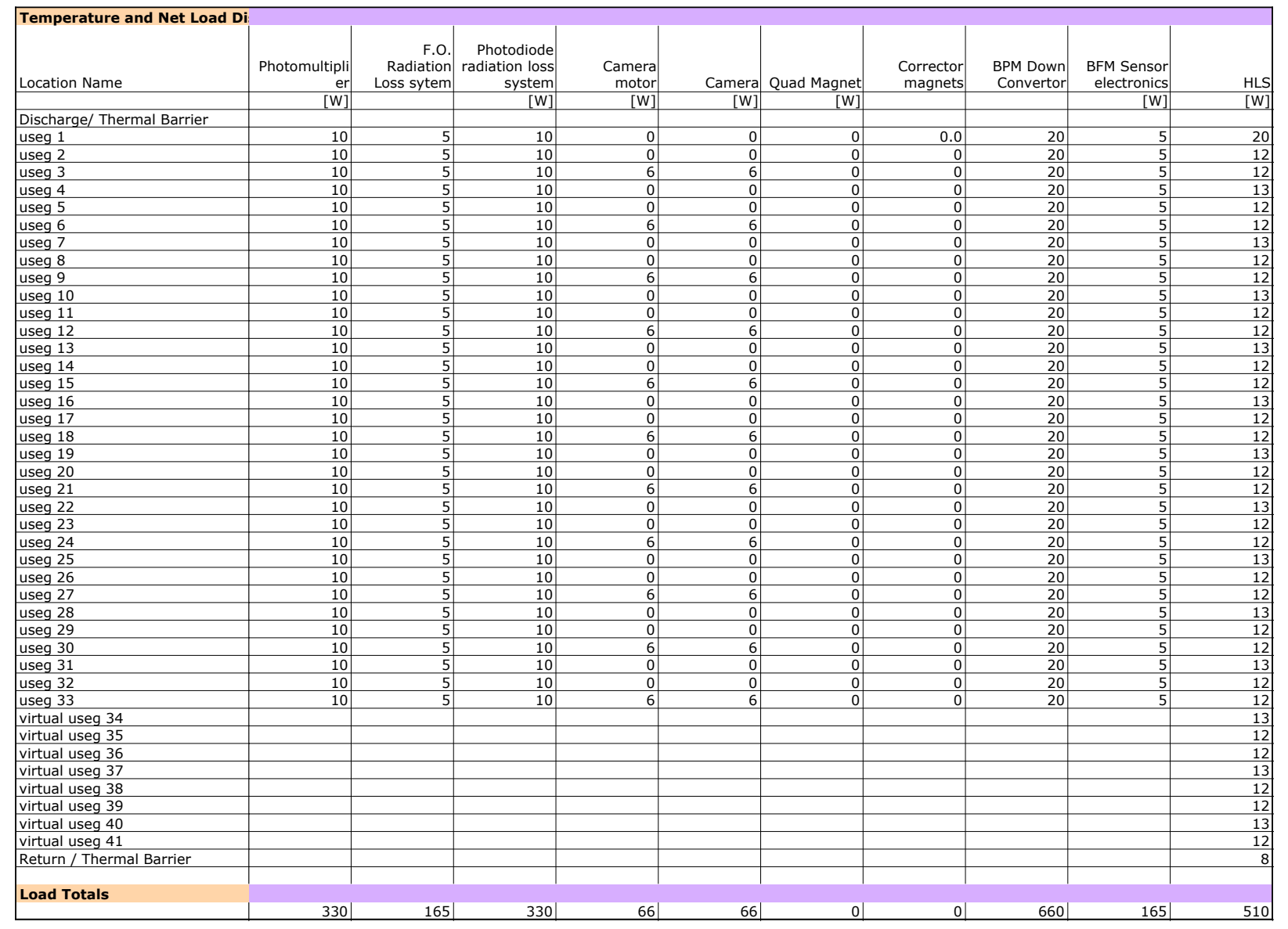




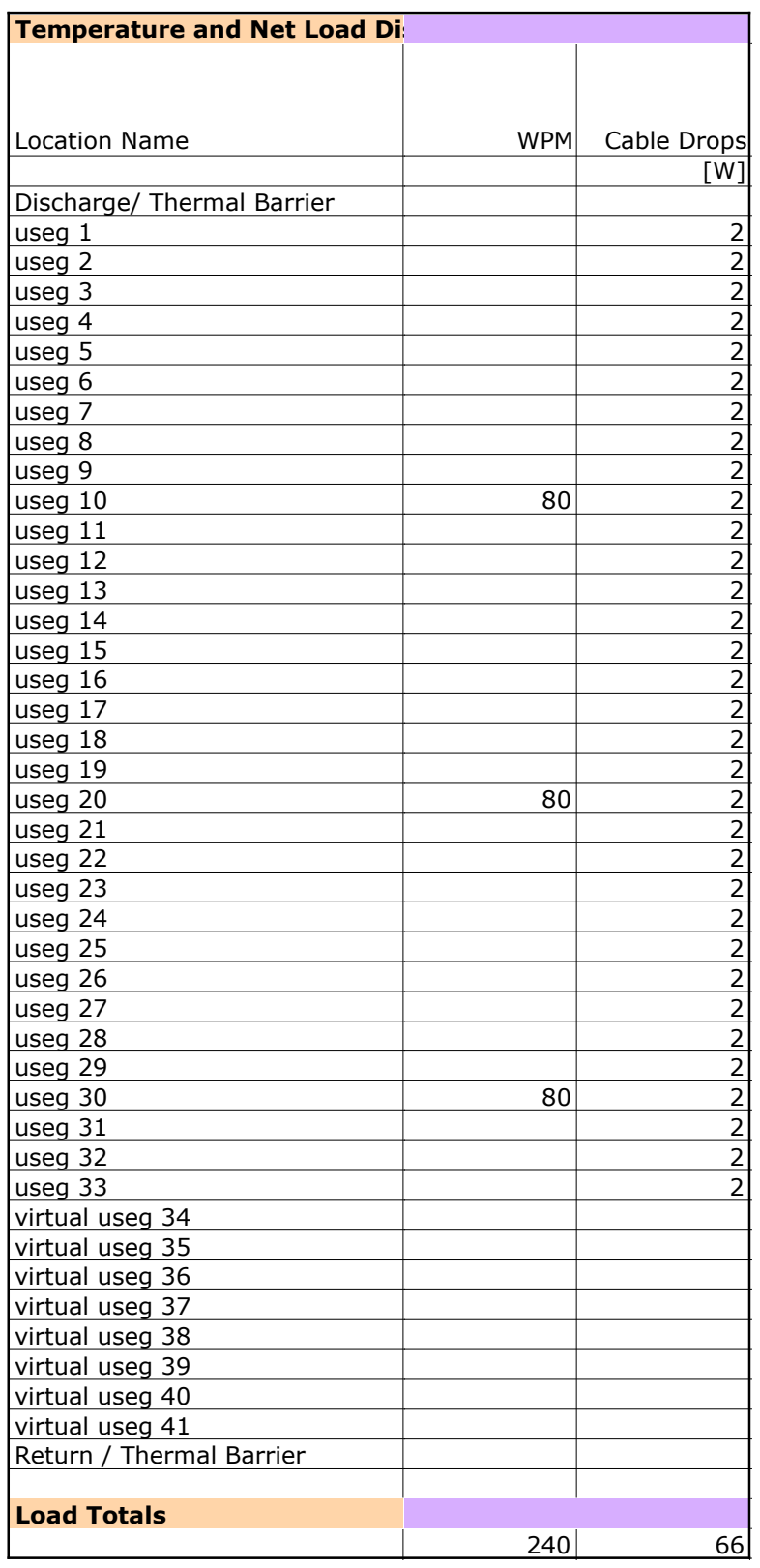

